Original Article

\title{
Effect of interferential current therapy on forward head posture
}

\author{
Ye-Jin Chol ${ }^{1)}$, Hee-Jung Kim ${ }^{1)}$, Sun-young Han, BHc, PT ${ }^{1)}$, Bo-RAm Chol, PhD, $\mathrm{PT}^{1 \text { )* }}$ \\ 1) Department of Physical Therapy, College of Health and Welfare, Silla University: \\ 315 Euisaengmyung-gwan, 700 Bakyangdae-ro, Sasang-gu, Busan 46958, Republic of Korea
}

\begin{abstract}
Purpose] The purpose of this study was to examine the effects of interferential current therapy on the shoulder muscles of subjects with forward head posture. [Subjects and Methods] Thirty volunteers (15 forward head posture, 15 control) participated in this study. Interferential current therapy treatment was conducted for $10 \mathrm{~min}$, three times per week, for 3 weeks on both the upper trapezius and levator scapulae. Subjects were measured anterior both acromion distance and posterior both acromial distance using a ruler, and the forward head posture angle using an electronic application. [Results] Both groups showed significant increases in anterior acromial distance, and decreases in posterior acromial distance and forward head posture angle. [Conclusion] Subjects were concluded that electrical therapy could improve structural alignment; therefore, the implementation of interferential current therapy is expected to be effective for the treatment of forward head posture.

Key words: Forward head posture, Interferential current therapy, Round shoulder
\end{abstract}

(This article was submitted Oct. 13, 2017, and was accepted Dec. 12, 2017)

\section{INTRODUCTION}

Forward head posture (FHP) changes muscle balance of shoulder and alignment of scapular ${ }^{1)}$. As a result, upper trapezius, levator scapula, pectoralis muscles become shorter, and longus coli and capitis, lower trapezius and rhomboid muscles become weaker such as 'upper crossed syndrome'2). Patients with FHP complaint cervical joint and overuse muscles pain causing overall imbalance activation ${ }^{3}$. Previous studies that examined FHP treatment focused on stretching pectoralis muscles and strengthening of lower trapezius muscle. However, despite similar exercise programs, contrasting results were reported $^{4,5)}$. The discrepancy may be attributable to individual differences among subjects because, due to the nature of the exercises, the subjects had to actively perform the exercises instead of passively receiving treatment. Treatments involving active exercise do not always produce positive outcomes ${ }^{2)}$. Thus, we suggest that passive treatments, such as interferential current therapy (ICT), allow for control of individual differences during treatment, reducing the effects of individual variation more effectively than is possible with active exercise. ICT is a common modality used to muscle relaxation and pain relief ${ }^{6}$. However, effect of ICT on change the alignment of scapular in patient with FHP have been questioned. Therefore, the purpose of this study was to examine the effects of ICT on changes in FHP.

\section{SUBJECTS AND METHODS}

Subjects were divided into FHP and normal head posture (NHP) groups based on the neck disability index (NDI) scores and the ear-to-acromion length $(\mathrm{EAL})^{5}$. The FHP group ( $\mathrm{n}=15$; age: $22.5 \pm 0.2 \mathrm{yrs}$, NDI: $10.27 \pm 1.47$, EAL: $\left.3.27 \pm 0.57 \mathrm{~cm}\right)$ and the NHP group ( $\mathrm{n}=15$; age: $20.8 \pm 0.3 \mathrm{yrs}$, NDI: $14.03 \pm 2.71$, EAL: $1.86 \pm 0.22 \mathrm{~cm}$ ) included only participants with no history of neck or shoulder surgery in the past 6 months and no musculoskeletal problems. The study received ethics

*Corresponding author. Bo-ram Choi (E-mail: baram@silla.ac.kr)

(C)2018 The Society of Physical Therapy Science. Published by IPEC Inc.

This is an open-access article distributed under the terms of the Creative Commons Attribution Non-Commercial No Derivatives (by-nc-nd) License. (CC-BY-NC-ND 4.0: https://creativecommons.org/licenses/by-nc-nd/4.0/) 
approval from the Human Research Ethics Committee of Silla University (1041449-201605-HR-003). ICT (Biotron-DX7, DMC Corp., Korea) was set at 100 bps for 15 min using the manual ICT mode ${ }^{7}$. Electrodes were attached to bilateral upper trapezius and levator scapulae. ICT was implemented three times a week for 4 weeks. The FHP application (FHP Center, SD Net Corp., Korea) was used to measure the FHP angle. This application can measure the tilt angle of the FHP by taking a photograph. The larger the FHP angle is, the more severe the FHP. The ear-to-acromion length (EAL), anterior both acromion distance (AAD) and posterior both acromion distance (PAD) were measured using a ruler. EAL was measured vertical distance between ear and acromion. AAD and PAD was measured anterior and posterior distance between right and left acromion. The difference between these two measures (i.e., PAD-AAD) was positively associated with FHP severity. Data analysis was conducted using SPSS ver. 20.0 for Windows. Paired t-tests were conducted to assess within-group changes after ICT in FHP angle, AAD, and PAD. Independent t-tests were carried out to compare the changes in FHP angle, AAD, and PAD after ICT between the two groups. The significance level was set at $\alpha=0.05$.

\section{RESULTS}

$\operatorname{FHP}\left(5.3 \pm 3.1^{\circ}\right.$ to $\left.3.6 \pm 2.9^{\circ}\right)$ and $\operatorname{PAD}(36.4 \pm 3.9$ to $35.93 \pm 3.9 \mathrm{~cm})$ decreased significantly, and $\mathrm{AAD}(32.5 \pm 3.3$ to 33.0 $\pm 3.4 \mathrm{~cm})$ increased significantly in the NHP group. Moreover, FHP $\left(8.7 \pm 2.8^{\circ}\right.$ to $\left.6.9 \pm 3.1^{\circ}\right)$ and $\operatorname{PAD}(35.3 \pm 2.9$ to $34.8 \pm$ $3.0 \mathrm{~cm})$ decreased significantly, and AAD $(32.2 \pm 2.4$ to $33.8 \pm 2.5 \mathrm{~cm})$ increased significantly in the FHP group. However, the changes in FHP, AAD, and PAD following ICT did not differ significantly between groups.

\section{DISCUSSION}

A previous study of upper trapezius muscle treatment for FHP found more positive effects on muscle relaxation and pain reduction with ICT than with transcutaneous electrical nerve stimulation ${ }^{7}$. In addition, ICT treatment induce relaxation of the upper trapezius muscles at rest and during functional activity ${ }^{8}$. It is theorized that the application of ICT in this study also induced relaxation of the shortened muscles in including levator scapulae and upper trapezius resulting in decreased FHP angle and PAD in both FHP and NHP groups. In an exercise study of patient with FHP, utilizing a 12-repetition regimen and a three-set program of strengthening (deep cervical flexors and shoulder retractors) and stretching exercises (cervical extensors and pectoral muscles) four times a week for 10 weeks had no significant exercise effect ${ }^{4}$ ). This may have been because there was a time limit for completing the exercises, and most of the exercises were too hard to follow, which made experimental control of the exercises difficult. The participation rate was high when physiotherapists monitored participants' performance, but it was low when the participants performed the exercise at home. In contrast, in our study, interferential current therapy was a passive treatment, always implemented in the laboratory. Our study showed more effective results possibly because the intervention was better controlled in our study than that of previous study on active exercises. In conclusion, the implementation of ICT may be an effective treatment for the patients with FHP.

\section{Conflict of interest}

None.

\section{REFERENCES}

1) Greenfield B, Catlin PA, Coats PW, et al.: Posture in patients with shoulder overuse injuries and healthy individuals. J Orthop Sports Phys Ther, 1995, 21: 287-295. [Medline] [CrossRef]

2) Neumann DA: Kinesiology of the musculoskeletal system-e-book: foundations for rehabilitation. Elsevier Health Sciences, 2013.

3) Moore MK: Upper crossed syndrome and its relationship to cervicogenic headache. J Manipulative Physiol Ther, 2004, 27: 414-420. [Medline] [CrossRef]

4) Harman K, Hubley-Kozey CL, Butler H: Effectiveness of an exercise program to improve forward head posture in normal adults: a randomized, controlled 10-week trial. J Manual Manip Ther, 2005, 13: 163-176. [CrossRef]

5) Lynch SS, Thigpen CA, Mihalik JP, et al.: The effects of an exercise intervention on forward head and rounded shoulder postures in elite swimmers. Br J Sports Med, 2010, 44: 376-381. [Medline] [CrossRef]

6) Fuentes JP, Armijo Olivo S, Magee DJ, et al.: Effectiveness of interferential current therapy in the management of musculoskeletal pain: a systematic review and meta-analysis. Phys Ther, 2010, 90: 1219-1238. [Medline] [CrossRef]

7) Acedo AA, Luduvice Antunes AC, Barros dos Santos A, et al.: Upper trapezius relaxation induced by TENS and interferential current in computer users with chronic nonspecific neck discomfort: an electromyographic analysis. J Back Musculoskeletal Rehabil, 2015, 28: 19-24. [Medline] [CrossRef]

8) Silva, Ana Paula Moura Campos Carvalho, Acedo AA, Antunes ACL, et al.: Electromyography analysis of upper trapezius relaxation induced by interferential current in subjects with neck discomfort. J Appl Res, 2011, 11: 20-29. 